\section{EMBRYRIDDLE}

Aeronautical University

SCHOLARLY COMMONS
Journal of Aviation/Aerospace

Education \& Research

Volume 19

Number 2 JAAER Winter 2010

Article 5

Winter 2010

\title{
Organizational Capacity and Progress Plateaus in the Flight Training Environment
}

\author{
Michael J. Wetmore \\ Brett Jackman \\ James F. Savard
}

Follow this and additional works at: https://commons.erau.edu/jaaer

\section{Scholarly Commons Citation}

Wetmore, M. J., Jackman, B., \& Savard, J. F. (2010). Organizational Capacity and Progress Plateaus in the Flight Training Environment. Journal of Aviation/Aerospace Education \& Research, 19(2). https://doi.org/ 10.15394/jaaer.2010.1373

This Article is brought to you for free and open access by the Journals at Scholarly Commons. It has been accepted for inclusion in Journal of Aviation/Aerospace Education \& Research by an authorized administrator of Scholarly Commons. For more information, please contact commons@erau.edu. 


\title{
ORGANIZATIONAL CAPACITY AND PROGRESS PLATEAUS IN THE FLIGHT TRAINING ENVIRONMENT
}

\author{
By
}

Michael J. Wetmore, Brett Jackman, and James F. Savard

\begin{abstract}
Capacity is the ability of an organization to achieve its overall mission and satisfy stakeholder expectations. Stakeholders in a flight training organization include the owners and/or their representatives, flight school managers, instructor pilots, and the student pilots. This study was an examination of the organizational capacity of student pilots through a progress plateau theoretical lens using a mixed methodological approach and participants from a collegiate aviation program. Student pilot progress plateaus were found to have an adverse unrealized capacity consequence for the stakeholders in the organization. Recommendations to improve organizational capacity include the identification of progress plateaus utilizing flight training progress charts followed by the intervention of flight school leaders to resolve the plateau.
\end{abstract}

\section{Introduction}

Organizations can have many stakeholders. In a flight training organization, the owners, managers, instructor pilots, and student pilots constitute some of the major stakeholders. Each of these stakeholder groups is likely to have a different viewpoint in regards to measuring organizational capacity.

Flight training organization owners, who are usually represented by chairs and deans or other executives in a collegiate program, might point to total enrollment numbers as the ultimate measure of capacity. The sheer volume of students enrolled equates to operating at or near maximum capacity. Owners may also like to note total enrollment growth from year to year as evidence of capacity building.

The managers of a flight training organization, typically embodied by directors of flight operations or chief flight instructors, might point to certain statistics such as the aircraft utilization rate as a measure of organizational capacity. These managers may also use year-to-year increases in the total number of hours flown as evidence of positive trending capacity building.

The capacity viewpoint of instructor pilots is plausibly focused more on individual performance as an organizational metric. Flight instructors are more likely to use their total flight hours logged per month as a measure of organizational capacity. Instructor pilots might look for increases in their total student load from semester to semester as evidence of capacity building.

But, how would the student pilots in a flight training organization respond to a question of whether the organization is performing at or near maximum capacity? Their viewpoint is probably markedly different from the other stakeholders in the flight training organization. Typically, student pilots are not concerned about total enrollment numbers or aircraft utilization rates, or how much flight time their instructor pilot is building every month. Most student pilots would probably point to their number of hours flown every semester or every year as a measure of their personal capacity in the organization. Student pilots are likely to use their rate of progress through the flight training program, the number of certificates and ratings earned over time, as evidence of capacity utilization. Problem Statement

The problem to be addressed is that there is not a clearly defined, easily employed, and statistically meaningful paradigm with which to measure student pilot capacity within flight training organizations. The capacity measures employed by other stakeholders in flight training organizations such as total enrollment, aircraft utilization 
rates, and instructor pilot student loads have little bearing on whether or not a student pilot is realizing the full capacity of the program.

\section{Purpose Statement}

The purpose of this investigation was twofold. First, this study gauged student pilot organizational capacity levels by employing quantitative measures of flight training progress plateaus in a flight training organization. Second, this study identified and analyzed the phenomena that result in progress plateaus and diminished organizational capacity from the student pilot perspective. Student pilot degree plan goal achievement benefits all of the stakeholders in the organization. Thus, the ultimate purpose of this research was to provide flight training organizations with the tools needed to optimize student pilot capacity.

Significance

Flight training organizations. One of the primary objectives of any business is to achieve and maintain profitability. In the business of flight training, the student pilots are the customers. Progress plateau information can benefit the flight training organization by improving customer satisfaction and increasing organizational capacity levels.

Flight school managers. Flight school managers carry a heavy burden. They are answerable to the stakeholders within the organization. Flight school managers are held accountable for the business aspects of the flight school by the ownership. Instructor pilots look to the flight school leaders for guidance and supervision. Student pilots rely upon the flight school leaders for proper and timely mentorship. Progress plateau information would enable flight school leaders and managers to better serve all of the stakeholders within the organization.

Instructor pilots. In most flight training organizations, the flight instructors depend upon the student pilot customers for the dollars in their paychecks and the total flight time in their logbooks. The elimination or reduction of student pilot progress plateaus would benefit instructor pilots on both accounts.

Student pilots. Most student pilots enroll in a professional pilot training program to fulfill dreams, achieve goals, and commence a career in aviation. Progress plateaus represent flight training delays. Progress plateaus are obstacles that arise between the student pilots and the attainment of their goals. Thus, the elimination or reduction of progress plateaus would be of enormous benefit to student pilots.

\section{Key Definitions}

Organizational capacity. Capacity is the ability of an organization to achieve its overall mission and satisfy stakeholder expectations (Horton, 2003). For a flight training organization, the typical mission is to train professional pilots. The stakeholders are the ownership, leaders and managers, employees, instructor pilots, and the student pilots. Organizations build capacity through activities such as planning, preparation, development, assessment, scheduling, education, auditing, guidance, training, recruiting, and evaluating performance (Light, 2004).

Learning plateau. A learning curve is a measure of learning performance versus time. Typically, a learning curve is plotted with Time on the $x$-axis, and Learning Performance on the $y$-axis. A learning plateau is simply a flattening of the learning curve (Statt, 1998). This flattening of the learning curve indicates learning performance is static, and is not increasing despite the passage of time. In the flight training environment, learning plateaus can be due to variety of causes such as capability limits, skill consolidation, waning interest, or instructional method (Federal Aviation Administration, 1998).

Progress plateau. The term Progress Plateau is suggested by this study and should be considered as a learning plateau subtype. Instead of plotting Learning Performance on the y-axis, actual Flight Hours from a student pilot's logbook are plotted on the $y$-axis. Calendar Time remains the measure of the $\mathrm{x}$-axis. A plot of the flight hours versus time results in a flight training progress curve. Thus, the operational definition of a progress plateau is a flattening of the flight training progress curve. Based on the findings in this study, progress plateaus can be due to a variety of factors such as extracurricular activities, personal injury, instructor pilot conflicts, aircraft scheduling conflicts, stage check conflicts, lack of flight training funds, lack of motivation, classroom conflicts, employment conflicts, and weather.

Nature of the Study

This research is a mixed methods study involving senior level student pilots in a collegiate professional flight training program. Quantitative survey procedures were used to document and substantiate flight training progress plateaus within the study group. Qualitative phenomenological procedures were utilized to identify and categorize the causes of flight training progress plateaus within the study group.

\section{Quantitative Research Questions}

Can flight training progress plateaus be documented in the flight training environment? Can 
progress plateaus be measured? How often do progress plateaus occur? What is the typical duration of a progress plateaus? Are there any relationships among flight training organization variables? What effects do progress plateaus have on organizational capacity? Qualitative Central Questions

From the student pilot perspective, what are the main causes of progress plateaus in the flight training environment? From the viewpoint of the participants, how can these progress plateaus be eliminated or reduced?

\section{Methods}

\section{Methodological Approach}

Overview. This is a mixed methods investigation because it employs both quantitative and qualitative procedures (Creswell, 2009). Quantitative survey methods (Zikmund, 2003) were used to collect flight training numerical data related to total time and calendar time. Flight training progress plateau data were gathered using qualitative phenomenological methods (Trochim \& Donnelly, 2008).

This study is basic and applied in character (Wiersma \& Jurs, 2005). The study encompasses basic research because it adds to the existing body of knowledge associative with learning plateaus and organizational capacity. The study features applied research because it attempts to offer solutions to immediate, practical problems in the flight training environment.

Site of inquiry. This study was conducted at a university with a collegiate aviation program. Specific interview sites were chosen by the individual participants on or near campus in order to provide a comfortable setting, and to ensure and preserve anonymity.

Departmental records. Prior to the commencement of this investigation, departmental records were reviewed for enrollment information. Only total enrollment numbers were reviewed. The freshmen class sizes from the four years preceding the investigation are considered to be estimates because, at the time, not all of the freshmen enrolled in the program had officially declared a major.

Population and sample. The study population for this research was senior level students in a collegiate aviation professional pilot program with nearly 500 total aviation students. Senior level students were targeted because it was more likely that they would have the most quantitative and qualitative data to contribute regarding flight training progress. Of the 37 senior level students listed in departmental records, 34 students responded to Institutional Review Board (IRB) approved public notices and volunteered to participate. The confidence interval of responses to quantitative survey questions, or general level of accuracy, was $+/-4.85 \%$ at the $95 \%$ confidence level.

The theoretical population for this study is all student pilots in all types of professional pilot programs. The study population was composed of males and females, traditional and non-traditional students, a range of socioeconomic classes, and various ethnicities. As such, the characteristics of the study population represent a proximal similarity model (Trochim \& Donnelly, 2008) of the theoretical population.

Assumptions. The main assumption in this study was whether a participant could accurately remember the precise cause of a specific flight training delay by examining their pilot's logbook. This assumption was mitigated by the extraordinary recall of explicit details of flight training delays by the participants. This recall was aided by meticulous pilot logbook activity descriptions. The student pilots could literally point to their logbook and provide, without hesitation, an exact cause for a particular flight training delay.

Limitations. The major limitation to this study was that it only reviews the quantitative flight training data and the qualitative progress plateau explanations from one group of student pilots from one university. This limitation was moderated by the fact that the study population closely emulates the theoretical population in regards to gender, ethnicity, and socio-economic diversity.

\section{Quantitative Procedures}

Instrumentation. The quantitative portion of this investigation was conducted using a simple, cross-sectional, non-clustered, census survey of the study population. The survey was stratified in that only senior level students were surveyed. The survey instrument consisted of a calendar. Participants were asked to note their accumulated total flight times according to their calendar time in the program. Participants were also asked to make note of any flight training milestones such as stage checks and pilot certificates and/or pilot ratings earned.

Data collection. The quantitative surveys were distributed to the participants by mail. The surveys were returned to the researcher by mail over a two week period. Upon receipt, the surveys were briefly audited to ensure that the flight training data were complete and recorded in the proper format.

Data analysis. Total flight time and calendar time data were recorded on a spread sheet program. Statistical analysis was performed using the Statistical Procedures for the Social Sciences (SPSS ${ }^{*}$ ) statistical program (Norusis, 2004).

Measurements. The internal validity of the measurements was determined using content validity. 
Content validity relates to whether the instrument measures what it was intended to measure (Creswell, 2009). The instrument was intended to measure total flight time versus calendar time. This measure was internally validated by comparing reported logbook flight times to official flight training records.

The external validity of the measurements was established using a proximal similarity model. Proximal similarity occurs when the study population context is similar to the theoretical population context (Trochim \& Donnelly, 2008). This similarity of contexts allows for results to be generalized across poputation boundaries.

The internal reliability of the measurements was estimated using single-administration internal consistency procedures. Internal consistency was calculated from pairwise correlations between items (Norusis, 2004). Specifically, the internal reliability was estimated using Cronbach's alpha $(a)$.

The external reliability of the measurements was estimated using an inter-rater protocol. Inter-rater reliability estimates gauge the external consistency of a measurement (Trochim \& Donnelly, 2008). A small, informal panel of Subject Matter Experts (SME), consisting of aviation professors and certified flight instructors, were asked to review the instrumentation. The SME were in 100\% agreement that the relative simplicity of the instrument would provide consistent external measures of the flight training time construct.

Qualitative Procedures

Data collection. The participants were asked to select a time and place of their choosing for a face-to-face, one-on-one, interview with the researcher (Creswell, 2009). The participants were asked to bring their pilot's logbook to the interview. Student pilots at this flight school are assigned three flight training slots per week. The flight training time survey instrument was examined for nonutilized flight training slots. Official school holidays and semester breaks were not counted as flight training delays.

After identifying a flight training delay, the participants were queried as to the cause of the delay. The participants were allowed to consult their pilot logbooks as needed. The response, "I do not remember" or "I do not know" was deemed an acceptable answer. However, there was not a single instance of a participant not being able to provide an exact cause for an unutilized flight training slot.

A second interview with each participant was conducted after each participant in the study completed the initial interview. During the follow-up interview, the participants were asked to review their answers to check for accuracy. The participants were also given an opportunity to supplement or clarify their answers. At the end of the follow-up interview, the participants were given an opportunity to verify the believability of the findings.

Data recording. Qualitative data were recorded on the survey instrument in the form of field notes (Creswell, 2009). The observational data recording protocol consisted of the researcher identifying and highlighting flight training delays on the survey instrument followed by the participant's explanation as to the exact cause of the delay.

Data coding. Coding is the process by which answers are categorized and organized (Wiersma \& Jurs, 2005). This study employed pre-determined and emergent codes to categorize the flight training delay explanations (Creswell, 2009). The pre-determined codes were (a) lack of flight training funds, (b) aircraft scheduling, (C) waiting for stage checks, and (d) weather. Emergent codes included extracurricular activities, injury, motivation, schoolwork, and employment conflicts.

Verification. The credibility of qualitative research relates to whether or not the participants find the results to be believable (Trochim \& Donnelly, 2008). To establish credibility, the individual quantitative and qualitative results were reviewed by the participants during follow-up interviews. Without exception, the participants found the results to be credible and believable.

Transferability refers to whether or not the results of qualitative research can be generalized from the study population to the theoretical population. Transferability is primarily the responsibility of the audience (Trochim \& Donnelly, 2008). Flight training delays are commonplace in the flight training environment. The actual causes of the delays will probably vary from one flight training organization to the next. Thus, the results of this study are likely to be transferable. However, the degree of transferability can only be determined by the audience.

Dependability in qualitative research refers to whether or not the study adequately accounts for the everchanging context of the inquiry (Trochim \& Donnelly, 2008). This study employed an emergent coding design to account for the evolving context of the investigation and to ensure that the results were dependable.

The confirmability of qualitative research relates to whether or not others can verify the results of the study (Trochim \& Donnelly, 2008). A small panel of Subject Matter Experts consisting of aviation professors and flight instructors reviewed the data collected in this study. Without exception, the subject matter experts confirmed the objectivity of the attendant results. 


\section{Descriptive Statistics}

\section{Results and Findings}

Slot utilization rate. A flight training slot was defined as a scheduled opportunity for a student pilot to engage in a flight training lesson. The 34 senior rank student pilots in this study had a total of 10,881 flight training slots available to them during their enrollment in the program (see Table 1). The student pilots utilized 7,855 of these training slots. On average, the student pilots utilized 231 of the 320 available slots for a flight training slot utilization rate of $72 \%$. Conversely, the student pilots did not utilize $28 \%$ of the available flight training slots.

Reasons for not utilizing flight training slots. The number one reason given by the students for not utilizing a flight training slot was the lack of personal motivation (see Table 2). The lack of motivation (32\%) accounted for approximately one out of every three of the missed slots and about one out of every ten of the total slots. Interpersonal conflict (17\%) between the student pilot and his or her flight instructor was the second most common reason given for not utilizing a training slot. The lack of flight training funds (13\%), aircraft scheduling (11\%), waiting for a stage check to be scheduled $(9 \%)$, and schoolwork $(9 \%)$ were also common reasons for not utilizing a training slot. Weather (3\%), extracurricular activities (3\%), employment conflicts $(2 \%)$, and personal injuries ( $1 \%$ ) were also given as reasons for missing a training slot.

Frequency of students citing a specific reason. More than half $(53 \%)$ of the students cited the lack of personal motivation as a reason for not utilizing a flight training slot (see Table 3 ). Exactly half $(50 \%)$ of the student pilots failed to use a training slot due to conflicts with their instructor pilots. More than one out of three (38\%) student pilots missed training slots while waiting for stage checks to be performed. Weather (32\%), aircraft scheduling (29\%), and schoolwork (29\%) also affected a substantial number of student pilots. The lack of flight training funds $(12 \%)$, employment conflicts ( $9 \%)$, extracurricular activities $(6 \%)$, and personal injury $(6 \%)$ affected a smaller number of student pilots.

Flight training progress. The collegiate aviation program in this study publishes a degree plan as a guide for incoming professional pilot students. The degree plan lists specific flight training goals for each semester of enrollment such as the private pilot certificate ( 35 flight training hours) in the first semester, the instrument rating ( 35 flight training hours) in the second semester, the commercial pilot certificate (120 flight training hours) in the third, fourth, fifth, and sixth semesters, the multi-engine rating (15 flight training hours) in the seventh semester, and the flight instructor certificate (15 flight training hours) in the eighth semester. Each semester consists of 16 weeks. This ideal progress through the flight training program is shown graphically in Figure 1.

Quantitative Results

Flight training slots not utilized and total flight training slots. Despite the relatively small sample size, there was a statistically significant correlation between flight training slots not utilized and total flight training slots (see Figure 2). Student pilots with a larger number of flight training opportunities were more likely to have not utilized a higher number of training slots. The Pearson correlation coefficient $(r)$ of 0.67 was significant at the $1 \%$ level.

Slot utilization rates by group. The 34 student pilots in this study were divided into five groups based on their slot utilization rates (see Table 4). Group A had a 91$100 \%$ slot utilization rate and consisted of $24 \%$ of the students. Group B had an $81-90 \%$ slot utilization rate and consisted of $17 \%$ of the students. Group $\mathrm{C}$ had a $71-80 \%$ slot utilization rate and consisted of $17 \%$ of the students. Group D had a $61-70 \%$ slot utilization rate and consisted of $21 \%$ of the students. Group E had $a \leq 60 \%$ slot utilization rate and consisted of $21 \%$ of the students.

Degree plan goal achievement. One-way Analysis of Variance (ANOVA) testing indicated a statistically significant relationship between the group flight training slot utilization rate and degree plan goal achievement (see Table 5 and Figure 3). Student pilots with a high rate of training slot utilization were more likely to meet the degree plan goals. The significance of this relationship was .009 at the $1 \%$ level.

Student retention rate. Departmental enrollment records indicated an estimated 126 freshman students enrolled in the program four years prior to this study (see Table 6). Including those students who did not participate, the senior class size at the time of this study was 37 . Of these 37 students, 18 were from the original freshman class and 19 were transfer students. Thus, the estimated retention rate from the freshman to the senior class was $14 \%$.

\section{Qualitative Findings}

Personal motivation. The lack of personal motivation accounted for $32 \%$ of the flight training slots not utilized and affected $53 \%$ of the student pilots (see Tables 2 \& 3). The typical student pilot response coded for not utilizing a slot due to personal motivation was some variation of the phrase, "I just didn't feel like flying." The specific reasons given for not feeling like flying were as unique as the individual. Some cited the loss of a family member. Others referred to the ending of a personal relationship. A number of student pilots mentioned being 
"fed up" with flight school politics. Finally, quite a few indicated that the lack of progress in their flight training led to a lack of motivation to keep flying.

Instructor pilot conflicts. Interpersonal conflicts between the student pilots and their instructor pilots accounted for $17 \%$ of the training slots not utilized and affected $50 \%$ of the student pilots (see Tables $2 \& 3$ ). The typical student pilot comment referencing this issue was, "I didn't feel like flying with my assigned flight instructor." Specific reasons were unique to the individual. At times the conflict was due to a clash of personalities. Some student pilots even acknowledged that the conflict was their fault. However, more often the conflict was due to the way some flight instructors made their students feel. Some instructors were habitually late to flight lessons or failed to show up for lessons without notifying the student. Some instructors created unpleasant cockpit environments by being derisive of a student's performance. A very common source of conflict was that some of the student pilots beleived their instructors were using the flight lessons to "build time" for their own benefit at the expense of the student; a situation one student summarized by saying, "I stopped flying with my instructor that semester because it was a waste of time. I wasn't getting my money's worth."

Flight training funds. The lack of flight training funds accounted for $13 \%$ of the training slots not utilized and affected $12 \%$ of the student pilots (see Tables $2 \& 3$ ). The high cost of flight training and not having enough money to fly are familiar student pilot complaints that are postulated at most flight schools. However, the effect of flight training funds may not be as large as commonly believed. As one student stated, "Sometimes I told people (at the flight school) that I was out of money when I didn't want to fly (for other reasons)."

Aircraft scheduling. Not having a suitable aircraft available at the designated time for a flight lesson accounted for $11 \%$ of the training slots not utilized and affected $29 \%$ of the student pilots (see Tables $2 \& 3$ ). Not having an aircraft available for a flight lesson was particularly frustrating to those student pilots who had a strong desire to continue their flight training.

Stage checks. Waiting for a Part 141 stage check to be scheduled and performed accounted for $9 \%$ of the slots not utilized and affected $38 \%$ of the student pilots (see Tables 2 \& 3). Many of the student pilots who cited instructor pilot conflicts also made negative comments about the flight school management. These comments about flight instructors and managers could be interpreted as indicative of the antiauthority hazardous attitude on the part of the student (FAA, 1998).
Schoolwork. Canceling a flight lesson due to schoolwork accounted for $9 \%$ of the slots not utilized and affected $29 \%$ of the student pilots (see Tables $2 \& 3$ ). Missing a flight lesson due to schoolwork was very common near the end of a semester just before final exam week.

Weather. Adverse weather conditions unsuitable for flight training accounted for just $3 \%$ of the slots not utilized and affected $32 \%$ of the student pilots (see Tables 2 \& 3). The more ambitious student pilots did not let adverse weather affect their training. These student pilots used bad weather days to complete a flight lesson using one of the school's flight simulators or to conduct a required ground school lesson. In addition, students with high slot utilization rates tended to reschedule lessons missed for any reason; including weather.

Extracurricular activities. Participation in officially sanctioned, extracurricular activities accounted for $3 \%$ of the slots not utilized and affected just $6 \%$ of the student pilots (see Tables $2 \& 3$ ). Both of the student pilots in this category were members of the university's football team. As one of the players commented, "My football scholarship is putting me through college. During the season, football is more important than flying. I can always make up flight lessons. I can't make up games or practices."

Employment conflicts. Missing a flight lesson due to a part-time job accounted for $2 \%$ of the slots not utilized and affected $9 \%$ of the student pilots (see Tables $2 \& 3$ ). Only 3 of the 34 students in this study described themselves as, "Working their way through college." For these student pilots, there were times when the demands of their employers created an unavoidable conflict with their scheduled flight training slot.

Injury. A personal injury accounted for just $1 \%$ of the slots not utilized and affected only $6 \%$ of the student pilots (see Tables $2 \& 3$ ). One of the student pilots injured a leg in a bicycle accident. Another student pilot injured an arm while skateboarding. Both missed some flight lessons while recuperating.

\section{Conclusions \\ Flight Training Capacity and Stakeholders}

Overview. Over the course of their careers in a professional pilot program, the student pilots in this study failed to utilize $28 \%$ of their flight training opportunities (see Table 1). These missed opportunities likely had an adverse effect on all of the stakeholders in the Flight Training Organization (FTO) in regards to organizational capacity.

Flight training organization owners. The $28 \%$ flight training slot non-utilization rate represents a substantial amount of lost capacity for the FTO ownership 
stakeholders (see Table 1). Moreover, the slot nonutilization rate may be indicative of additional unrealized capacity. Departmental enrollments records indicate only a $14 \%$ student retention rate between the freshman and senior years (see Table 5). Many of the subjects in this study remarked on how the reasons for not utilizing a flight training slot almost led them to quit the program entirely. In addition, many of the subjects mentioned that they knew former classmates who had dropped out of the program for one or more of the reasons listed for not utilizing a slot (see Table 3).

Flight training organization manugers. Every semester, on average, $28 \%$ of the flight training slots were not utilized. This represents a considerable amount of wasted capacity for the flight training organization. Wasted capacity can make it difficult for the flight school management to properly manage the university flight school's budget and resources. For example, flight school management is required to provide the flight training aircraft, training facilities, and support personnel for all of the scheduled flight lessons. These flight school resources are wasted when the flight training slots are not utilized. Wasted resources can only result in a reduced profit margin for the university flight school.

Instructor pilots. A low flight training utilization rate can result in unfulfilled capacity for the flight instructors in two ways. First, it can reduce their income by reducing the number of hours flown with the student pilot customers in any given pay period. Second, it can reduce the total number of hours flown in any given time period; thus delaying the instructor pilot's ability to apply for professional pilot jobs that list minimum total flight time requirements as a qualification for application.

Student pilots. Of the 34 student pilots in this study, only $13(38 \%)$ realized their degree plan goals (see Table 5). In other words, $62 \%$ experienced unfulfilled capacity. Failing to achieve degree plan goals can have a dramatic effect on the personal lives and professional careers of student pilots. One of the subjects provided a fitting summary for the group of student pilots who did not meet the degree plan goals.
Sometimes I think that my
dreams of a flying career are pretty much over. I'm supposed to graduate in three months. I've got enough flight training and total flight time to graduate. But, I don't have a flight instructor certificate (which is not required for graduation) or

enough total flight time hours to actually get a flying job. Without access to student loans, I'm not going to have enough money to finish my flight training. And to make matters worse, I'm going to have to start paying on the student loans I've already taken out. I don't know what I'm going to do.

Measuring Flight Training Capacity

Total flight training slots not utilized. Tracking the total number of flight training slots not utilized by an individual student pilot is probably not a good measure of flight training capacity for student pilots. There is a statistically significant correlation between training slots not utilized and total training slots (see Figure 2). This indicates that it is not unusual for a student pilot who has had a high number of training opportunities to have also missed a relatively high number of flight lessons.

Flight training slot utilization rate. The flight training slot utilization rate is probably a better measure of flight training capacity for student pilots. The flight training slot utilization rate is a unit-less measure that accounts for the volume of training opportunities (see Table 4). In addition, student pilots with high slot utilization rates are more likely to achieve degree plan goals (see Table 5 and Figure 3). The flight training slot utilization rate can also be used as the basis to identify flight training progress plateaus.

Flight training progress charts. Perhaps the most effective and efficient method to measure flight training progress in regards to capacity evaluation is to plot total flight training time in hours versus flight training program duration in weeks (see Figure 4). Student 9 was in slot utilization group $B$ (see Table 4) with a slot utilization rate of $89 \%$. An examination of the flight training progress chart shows that Student 9's flight training progress curve is nearly identical to the program's recommended flight training progress curve.

Progress Plateaus

Realized capacity. Approximately one out of three $(38 \%)$ of the student pilots in this study realized the capacity potential of the flight training program in regards to degree plan goal achievement (see Table 5). Charting the student pilot's flight time hours versus calendar time provides a graphical technique to examine flight training progress for any particular student through the program.

Student 29 in this study is an example of a student pilot who was able to realize and surpass the capacity potential of the program (see Figure 5). Student 29 was able 
to exceed the recommended ideal training schedule every semester. This student was able to complete the required certificates and ratings in two years instead of the recommended four. This student then worked as a flight instructor for the program during the junior and senior years. At the time of this study, Student 29 had accumulated enough total flight time to apply for First Officer positions with regional air carriers. Student 29 had the following comments in regards to achieving goals and realizing capacity.

\begin{abstract}
When I was a freshman, someone told me that the key to success was getting the flight instructor certificate as soon as possible. I took that advice to heart. I flew five or six times every week my freshmen and sophomore years and got my flight instructor certificate the following summer (after the sophomore year). You know, every day there was always a flight slot open on the schedule somewhere and there was always a flight instructor around who wanted to fly. Whenever I missed a flight lesson for weather or school or something, I always rescheduled the (flight) lesson. So really, I never missed any lessons. The way I look at it, a person has to spend (dollar amount) on flight training whether it takes two years or four years. Why not get it over with as quickly as possible and start making money and building time?
\end{abstract}

Unrealized capacity. Approximately two out of three $(62 \%)$ of the student pilots in this study did not realize the capacity potential of the flight training program in regards to degree plan goal achievement (see Table 5). Each of the students who did not realize the degree plan goals evidenced progress plateaus on their flight training progress charts.

The flight training progress of Student 5 in this study is a representative example of the student pilot group who did not realize their degree plan goals (see Figure 6). In the words of Student 5, the first semester (weeks 1-16) was "very productive" due to the fact that the student was able to earn the private pilot certificate in accordance with the recommended training schedule.

The first progress plateau occurred in the second semester (see Figure 6; weeks 17-32). According to Student 5 , "Me and my (second semester) flight instructor just didn't get along. It got to the point where I just didn't feel like flying." In the third semester (weeks 33-48), Student 5 was able to make good progress; " 1 had a really good instructor the first semester of my sophomore year." However, training progress encountered another plateau during the fourth and fifth semesters (weeks 49-80); "I had a lot of trouble getting past the stage checks and I just lost the motivation to keep at it (flight training)." Training progress picked up again in the sixth semester (weeks 81-96); "I could tell that I was falling behind my classmates and I wanted to catch up." In the seventh semester (weeks 97-112), Student 5's training progress encountered a nearly flat progress plateau.

I kind of just gave up that (seventh) semester. I could tell that I wasn't going to be able to finish my commercial certificate on time. And nobody (at the flight school) seemed to care if I was flying or not so I just stopped showing up for flight lessons.

\section{Recommendations}

\section{Identification}

All of the stakeholders in a flight school, from the owner representatives to the managers to the instructor pilots to the student pilots, can benefit from the realization of the student's capacity regarding degree plan goal achievement. In other words, student pilots who are not realizing the degree plan goals represent unfulfilled organizational capacity.

The first step to maximizing the capacity of student pilots, and thus the capacity of the organization, is the early identification of those students who are experiencing flight training progress plateaus. The early identification of progress plateaus is a relatively simple procedure when plotting flight training progress for an individual semester (see Figure 7).

Student 13's first week of flight training proceeded as expected (see Figure 7). The earliest indication of a problem occurred in the second week of training when there was no progress made. By week five, Student 13 had fallen well below the curve for ideal progress through the private pilot flight training program. By mid-term (week 8), a serious flight training problem was clearly evident according to the progress chart. This is how Student 13 described the 
first semester of flight training.

I almost dropped out (of the aviation program) that first semester. My flight instructor was super-critical and never let me fly the plane. Everything I did was wrong. I absolutely hated going to the airport (for a flight lesson). In the middle of the semester and again towards the end (of the semester), I just stopped going to the flight. lessons because flying wasn't any fun.

\section{Intervention}

The second step to maximizing the organizational capacity of student pilot flight training progress is for flight instructors and/or flight school managers to intervene once a progress plateau has been identified. A successful intervention can have dramatic effects on the flight training career of a student pilot.

Student 13's slot utilization rate for the first semester was $44 \%$. Student 13 's overall slot utilization rate for the entire program was $95 \%$. Student 13 was able to recover from a poor start in the first semester (see Figure 7) of flight training and actually achieve the program goals by the end of the junior year (see Figure 8); one year ahead of the recommended schedule. According to Student 13, the intervention occurred at the beginning of the second semester with the assignment of a new flight instructor.

Smith (pseudonym for the flight instructor) is without a doubt the world's greatest flight instructor. Smith turned everything around for me. The cockpit (environment) was pleasant and easy-going. Our flights (lessons) were always interesting and sometimes exciting. I learned something new every day. Smith made flying fun again. By the end of my freshmen year I had caught up with the other people in my class. By the end of my junior year I had my flight instructor certificate and then went to work part-time for the flight school my senior year. I owe it all (goal achievement) to Smith for getting me back on track.

\section{Summary}

Flight training progress plateaus adversely affect the organizational capacity of every stakeholder in a flight organization from the owners to the managers to the flight instructors to the student pilots. Some of the reasons given by student pilots for not utilizing a flight slot may seem to be unavoidable. However, some of the reasons given by student pilots for missing a flight lesson can and should be addressed by flight school leaders and instructor pilots.

The non-utilization of flight training slots due to certain reasons may seem to be inevitable. Delays due to weather and aircraft scheduling are going to occur in any flight school. The efficient scheduling of stage checks can be difficult for a flight school; especially when a large number of students reach a stage check point in their training at the same time. Exchanging flight lesson time for study time during final exam week may be a viable process for academically challenged students. For those students working their way through college or going to school on an athletic scholarship, scheduling conflicts may be inescapable. Finally, personal injuries are going to happen once in awhile to active individuals and time will be required to heal.

The lack of flight training funds is problematic. Student pilots are normally responsible for securing the funds required to complete their flight training. But, many of the students in this study noted that it took them several semesters to figure out the intricacies of the financial aid system. Several of these students mentioned that having some kind of financial aid advisor would have been beneficial.

Nearly half (49\%) of the flight training slots not utilized in this study were due to a lack of personal motivation and instructor pilot conflicts. Motivation and interpersonal conflicts are causes of flight training progress plateaus that can and should be addressed by flight school leaders and flight instructors on a case by case basis.

The specific cause for each missed flight lesson is as individual as the people involved. Therefore, there is no one single recommendation to address every case. However, some general guidelines can be established.

First, progress plateaus have to be identified as early as possible during flight training. Flight training progress charts are a simple and easy to use tool to identify progress plateaus (see Figures 4-8). Blank progress charts with an ideal progress curve based on the school's recommended training schedule can be constructed from any number of commonly available computer spreadsheet programs. These blank progress charts can be incorporated 
into the student pilot's flight training records. With an estimated 60 seconds of record-keeping per week, the flight instructor and/or the student pilot should be able to plot their weekly flight training progress.

The student pilots, flight instructors, and flight school leaders can then review and compare the student pilot progress charts to the program's ideal progress. By examining the progress chart, these flight school stakeholders should be able to determine whether or not the student pilots are realizing and utilizing the available capacity of the training program.

Once a flight training progress plateau has been identified, the next step is for the stakeholders to determine the causation of the plateau and to determine if there is a way to eliminate or reduce the identified cause. Potential solutions will be as varied as the problem. A change of instructors might resolve instructor-student conflicts. Financial aid counseling might address lack of flight training funds issues. Creative aircraft scheduling might solve extracurricular and employment conflicts. These are just a few examples of a long list of potential solutions.

Many of the students who cited a lack of motivation as a reason for missing flight lessons also noted that "no one at the flight school seemed to care" if the student was making progress or not. Just the simple act of a flight school leader noticing that a student pilot was not making progress, and making an inquiry as to the cause, might be the first step in getting these students back on the proper flight training progress track.

All of the stakeholders in a flight training organization benefit when the student pilots realize the full capacity of the program. However, the responsibility for achieving or exceeding full capacity need not rest solely with the student pilots. Other stakeholders in the organization can and should pro-actively participate and facilitate in this endeavor. Charting student pilot progress, identifying progress plateaus, and addressing the causes of the progress plateaus, will assist student pilots in the realization of their personal capacity; while building organizational capacity at the same time.

Analogous to any successful business entity, university flight schools should identify the needs of their customers, and subsequently provide a product or service that will satisfy those needs. The defined end-customers of a university flight school are students enrolled in aviation curricula. In many instances, the end-customer may also include individuals (e.g., parents) who are providing financial resources to the student customers. Organizations that strive to provide student-centric, efficient, and effective business practices can increase flight training capacity through the realization and use of organizational capacity databases and individual student-customer progress plateau charting in the flight training environment. $t$ 
Michael J. Wetmore is an assistant professor in the School of Business and Technology Management at Northcentral University. Dr. Wetmore holds commercial and flight instructor certificates with instrument and multi-engine ratings. He has 3300 hours of total flight time with 2400 hours of dual flight instruction given. He has endorsed approximately 135 pilots for various FAA check-rides ranging from private pilot to multi-engine flight instructor. His research interests include numerous publications in the subject areas of aviation education, aviation safety, and Crew Resource Management.

Brett Jackman is a Lieutenant Colonel in the United States Marine Corps. LtCol Jackman holds commercial and Airline Transport Pilot (ATP) certificates with multi-engine, instrument and rotary wing ratings. He has over 3500 flight hours in various austere environments, including combat, and $\mathbf{2 0 0 0}$ instructor hours. He has held the position as the training wing standardization instructor certifying instructors for five of six stages of primary and intermediate flight instruction. He was a designated instrument examiner for fixed and rotary wing flight, a designated examiner for the UH-1N and the unmanned aerial vehicle standardization evaluator for the Marine Corps. LtCol Jackman trained astronauts and flight controllers for the National Aeronautics and Space Administration on the space shuttle guidance, navigation, control and propulsion systems. His research interests include aviation policy, flight training, and aviation education.

James F. Savard is a retired naval aviator with over $\mathbf{4 0 0}$ day and night landings on United States and British aircraft carriers; and is a retired commercial airline captain. Dr. Savard has completed over 18,000 accident and incident flight hours and is a rated Air Transport Pilot (ATP) with experience on L-1011, A-300, B-757, DC-9, and B-727 aircraft. Dr. Savard also has over 25-years experience with three Fortune 500 companies, 18 in management and leadership capacities. Dr. Savard is a graduate of the United States Naval Academy in Annapolis, Maryland, and has been awarded a Master of Science in Management (MSM) from Regis University, a Master of Aeronautical Science (MAS) from Embry-Riddle Aeronautical University, and received his Ph.D. in Business Administration with specializations in Management and Aeronautical Science in 2007. His research interests include the disciplines of leadership, ethics, gender-stereotyping aviation education, Crew Resource Management, and Human Factors. 


\section{References}

Creswell, J.W. (2009). Research design: qualitative, quantitative, and mixed methods approaches. Thousand Oaks, CA: Sage.

Federal Aviation Administration. (1998). Aviation instructor's handbook. FAA-H-8083-9. Author.

Horton, D. (2003). Evaluating capacity development: Experiences from research and development organizations around the world. Ottawa, Canada: IDRC books.

Light, P.C. (2004). Sustaining nonprofit performance: The case for capacity building and the evidence to support it. Washington: Brookings Institution Press.

Norusis, M.J. (2004). SPSS 12.0 guide to data analysis. Upper Saddle River, NJ: Prentice Hall.

Trochim, W.M.K., \& Donnelly, J.P. (2008). The research methods knowledge base (3rd ed.). Mason, Ohio: Cengage Learning.

United States Department of Health and Human Services. (2009). Code of Federal Regulations, Title 45 public welfare, Part 46 protection of human subjects. Retrieved June 14, 2009, from

http://www.hhs.gov/ohrp/humansubjects/guidance/45cfr46.htm \#46.102

Wiersma, W., \& Jurs, S.G. (2005). Research methods in education (8th ed.). Boston: Pearson.

Zikmund, W.G. (2003). Business research methods (7th ed.). Mason, Ohio: Cengage Learning. 


\section{Tables}

\section{Table 1}

Flight Training Slot Analysis

Flight Training Slots: Senior Rank Student Pilots

\begin{tabular}{|c|c|c|c|}
\hline & Scheduled Slots & Slots Utilized & Slots Not Utilized \\
\hline Total (all student pilots) & 10,881 & 7,855 & 3,026 \\
\hline Mean (per student pilot) & 320 & 231 & 89 \\
\hline \multirow[t]{2}{*}{ Percent } & & $72 \%$ & $28 \%$ \\
\hline & & & $\mathrm{N}=34$ \\
\hline
\end{tabular}


Table 2

Reasons for Not Utilizing a Flight Training Slot Analysis

Flight Training Slots

\begin{tabular}{|c|c|c|c|}
\hline $\begin{array}{l}\text { Reason for } \\
\text { Not Utilizing a Flight Slot }\end{array}$ & Slots Not Used & $\begin{array}{c}\text { Percent of } \\
\text { Slots Not Utilized } \\
(3,026) \\
\end{array}$ & $\begin{array}{c}\text { Percent of } \\
\text { Total Slots } \\
(10,881)\end{array}$ \\
\hline Personal motivation & 976 & $32 \%$ & $9 \%$ \\
\hline Instructor pilot conflict & 507 & $17 \%$ & $5 \%$ \\
\hline Flight training funds & 385 & $13 \%$ & $4 \%$ \\
\hline Aircraft scheduling & 325 & $11 \%$ & $3 \%$ \\
\hline Waiting for stage check & 269 & $9 \%$ & $2 \%$ \\
\hline Schoolwork & 258 & $9 \%$ & $2 \%$ \\
\hline Weather & 105 & $3 \%$ & $<1 \%$ \\
\hline Extracurricular activities & 81 & $3 \%$ & $<1 \%$ \\
\hline Employment conflicts & 66 & $2 \%$ & $<1 \%$ \\
\hline \multirow[t]{2}{*}{ Injury } & 38 & $1 \%$ & $<1 \%$ \\
\hline & & & $N=34$ \\
\hline
\end{tabular}




\section{Table 3}

Quantity of Students Citing a Particular Reason Analysis

\begin{tabular}{|c|c|c|}
\hline $\begin{array}{c}\text { Reason for } \\
\text { Not Utilizing a Flight Slot }\end{array}$ & $\begin{array}{l}\text { Number of Students } \\
\text { Citing this Reason }\end{array}$ & $\begin{array}{c}\text { Percent of } \\
\text { Total Students } \\
\end{array}$ \\
\hline Personal motivation & 18 & $53 \%$ \\
\hline Instructor pilot conflict & 17 & $50 \%$ \\
\hline Flight training funds & 4 & $12 \%$ \\
\hline Aircraft scheduling & 10 & $29 \%$ \\
\hline Waiting for stage check & 13 & $38 \%$ \\
\hline Schoolwork & 10 & $29 \%$ \\
\hline Weather & 11 & $32 \%$ \\
\hline Extracurricular activities & 2 & $6 \%$ \\
\hline Employment conflicts & 3 & $9 \%$ \\
\hline \multirow[t]{2}{*}{ Injury } & 2 & $6 \%$ \\
\hline & & $\mathrm{N}=34$ \\
\hline
\end{tabular}




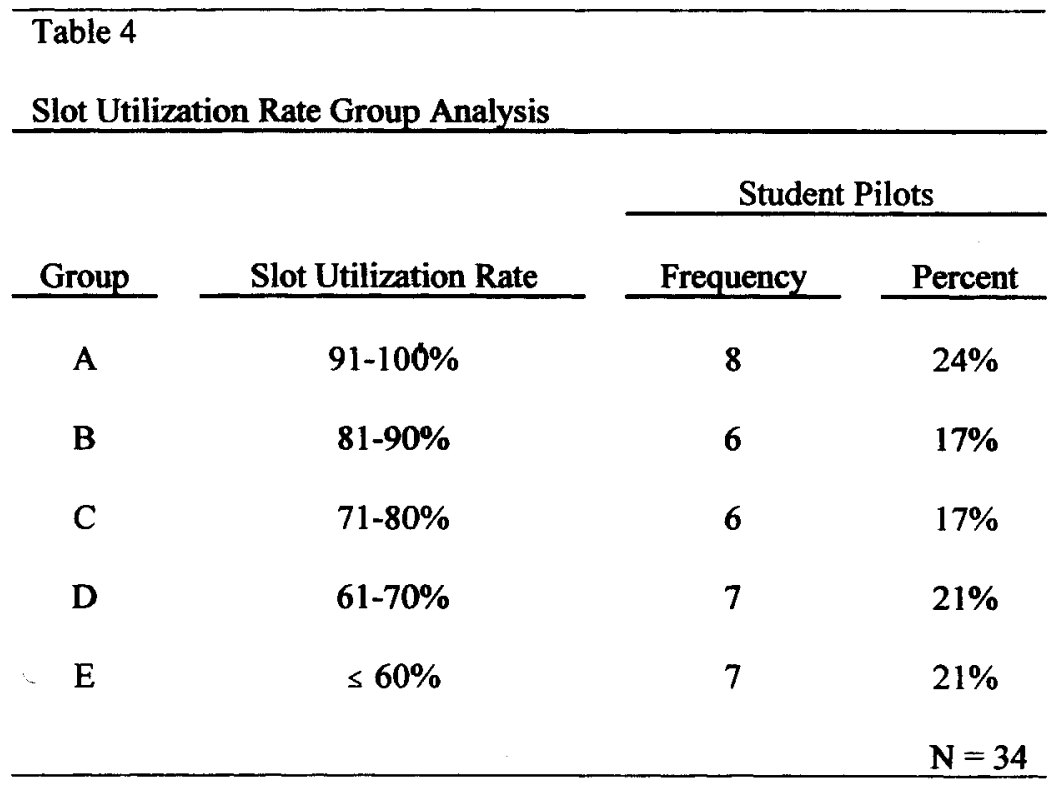




\section{Table 5}

Student Pilot Degree Plan Goals Realization Analysis

\begin{tabular}{|c|c|c|c|}
\hline \multirow[b]{2}{*}{ Group } & \multirow[b]{2}{*}{$\begin{array}{l}\text { Student Pilots } \\
\text { in the Group . }\end{array}$} & \multicolumn{2}{|c|}{$\begin{array}{c}\text { Student Pilots who } \\
\text { Achieved Degree Plan Goals }\end{array}$} \\
\hline & & Frequency & Percent \\
\hline A & 8 & 5 & $62 \%$ \\
\hline B & 6 & 3 & $50 \%$ \\
\hline C & 6 & 3 & $50 \%$ \\
\hline D & 7 & 2 & $29 \%$ \\
\hline $\mathrm{E}$ & 7 & 0 & $0 \%$ \\
\hline \multirow[t]{2}{*}{$\begin{array}{c}\text { Total } \\
\text { (all groups) }\end{array}$} & 34 & 13 & $38 \%$ \\
\hline & & & $\mathrm{N}=34$ \\
\hline
\end{tabular}




\section{Table 6}

Freshmen to Senior Class Estimated Student Retention Rate

\begin{tabular}{lcc}
\hline \multicolumn{1}{c}{ Parameter } & & $\begin{array}{c}\text { Number of } \\
\text { Students }\end{array}$ \\
\hline $\begin{array}{l}\text { Estimated incoming freshmen class size four years prior to this study } \\
\text { Senior class size at the time of this study (including those students who did not } \\
\text { participate in the study) }\end{array}$ & 126 \\
$\begin{array}{l}\text { Senior students in the senior class who transferred into the program } \\
\text { Students in the senior class from the original freshmen class }\end{array}$ & 19 \\
Estimated retention rate from the freshmen to the senior class & $14 \%$ \\
\hline
\end{tabular}


Figures

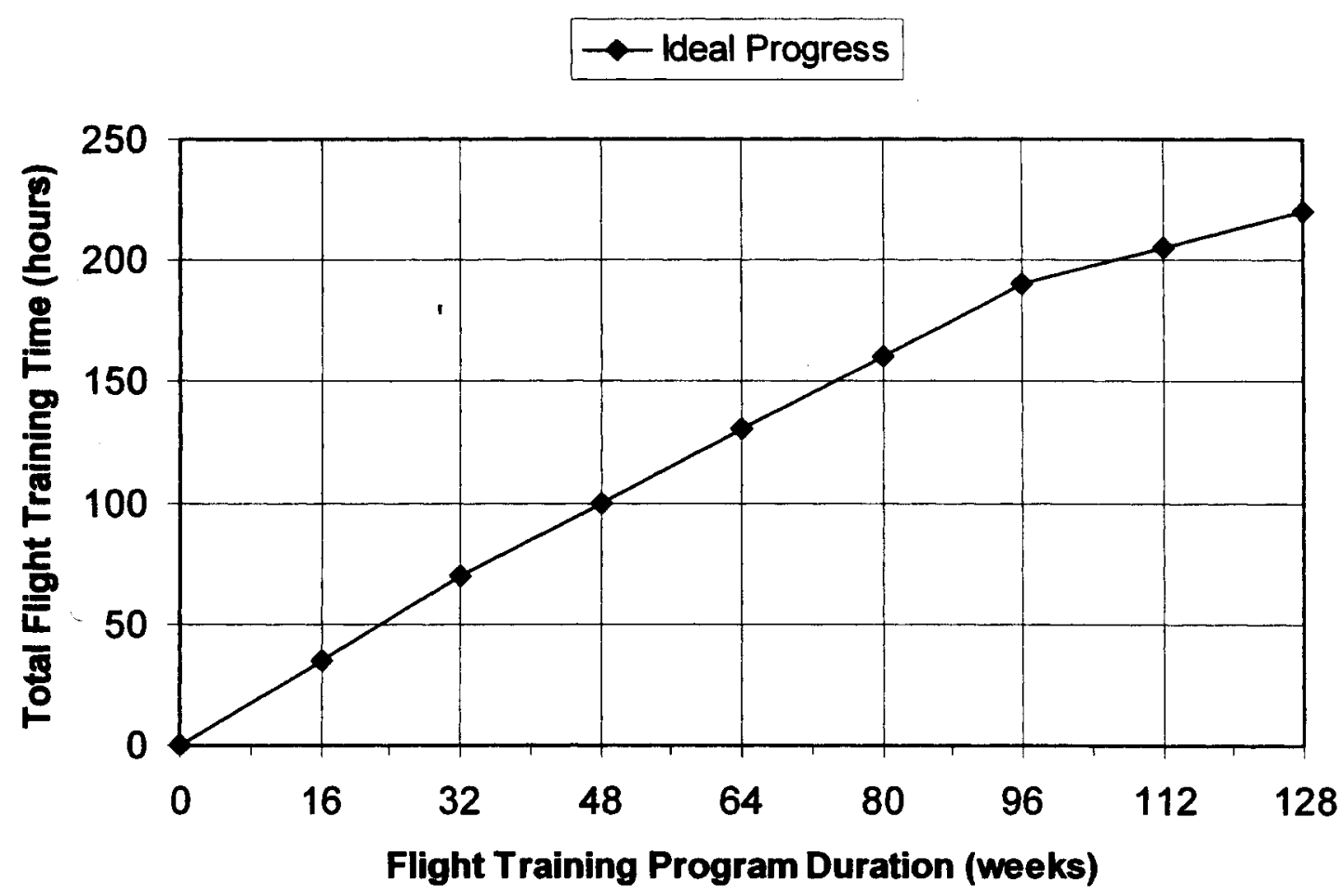

Figure 1: Plot of Total Flight Training Time in hours versus Flight Training Program Duration in weeks for a student pilot making ideal progress through the flight training program. One semester is equal to 16 weeks. 


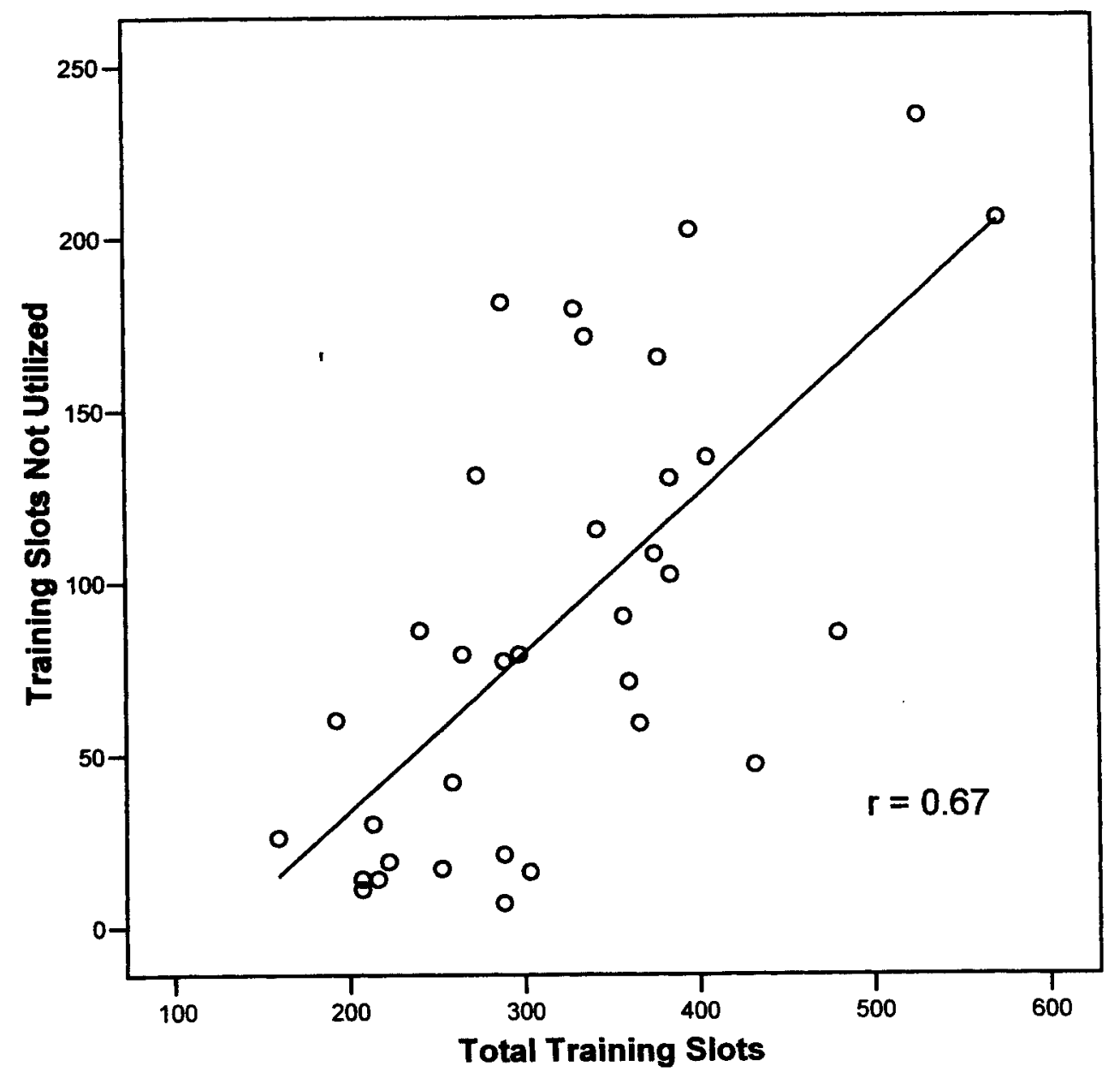

Figure 2: Scatter-plot of flight training slots not utilized versus total flight training slots with a linear best fit line. Pearson correlation coefficient $(r=0.67)$ statistically significant at the $1 \%$ level of significance. 


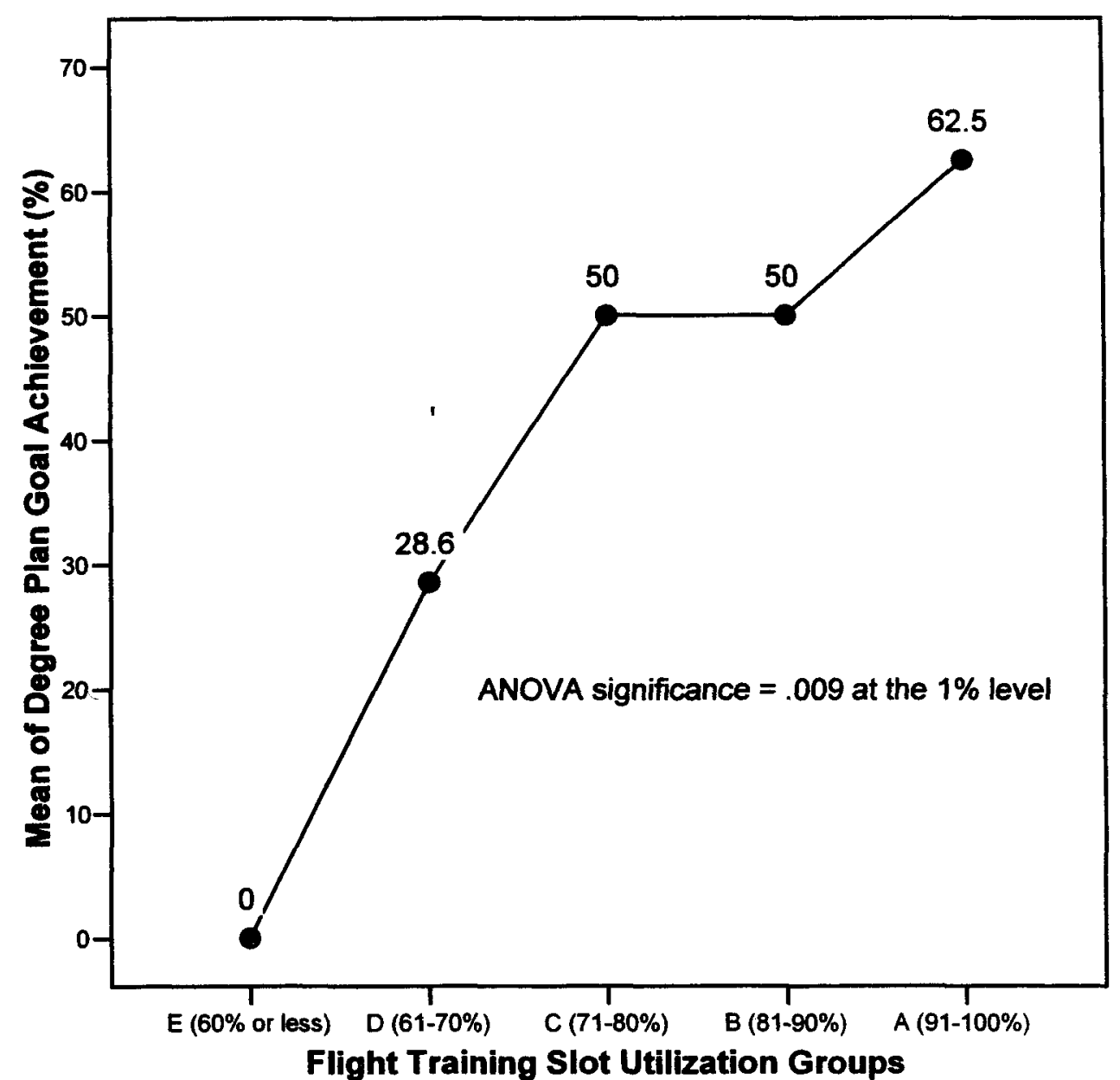

Flight Training Slot Utilization Groups

Figure 3: Means plot of Degree Plan Goal Achievement versus Flight Training Slot Utilization Groups. ANOVA statistically significance $=.009$ at the $1 \%$ level. 


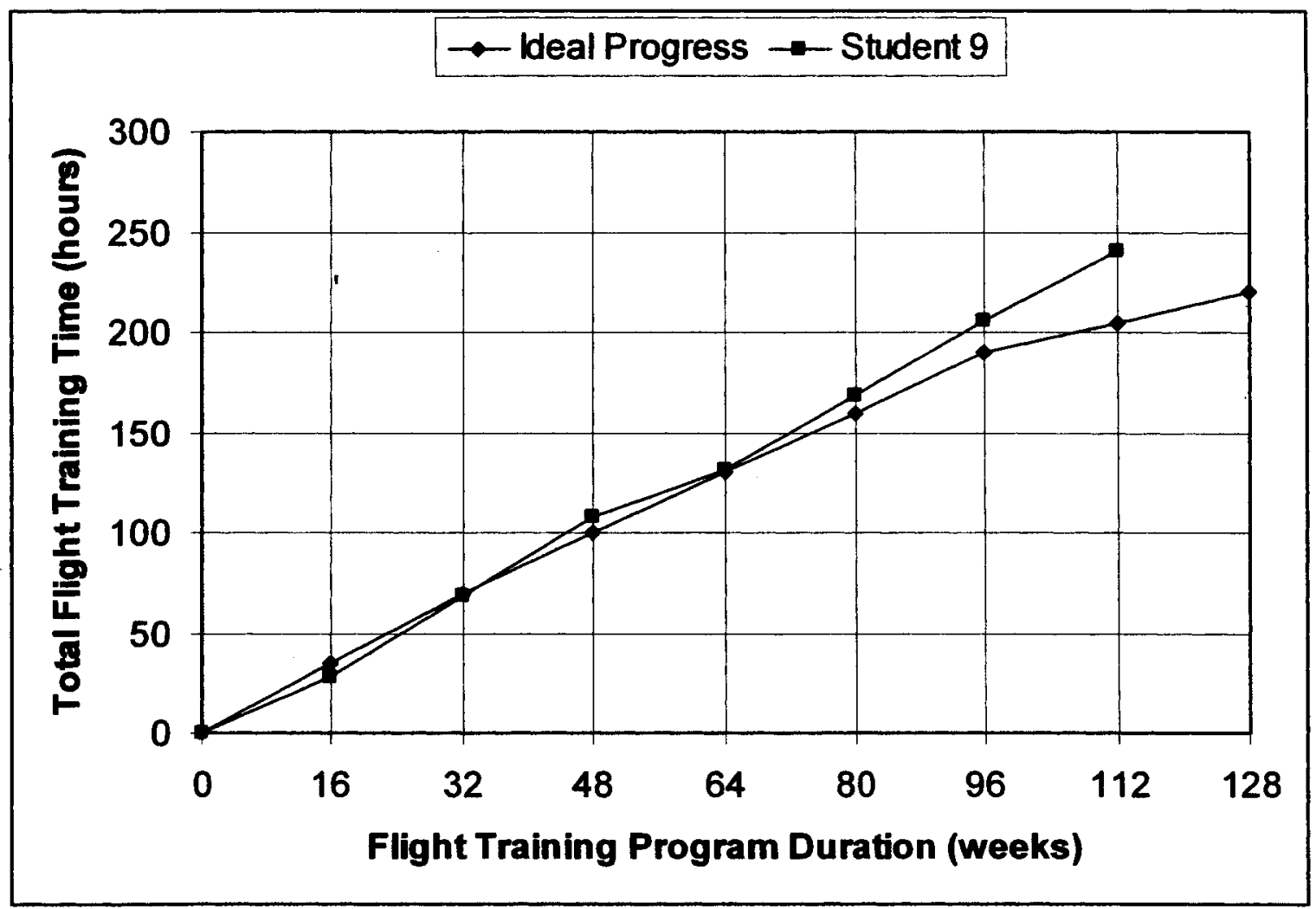

Figure 4: Example of a Flight Training Progress Chart (Student 9). 


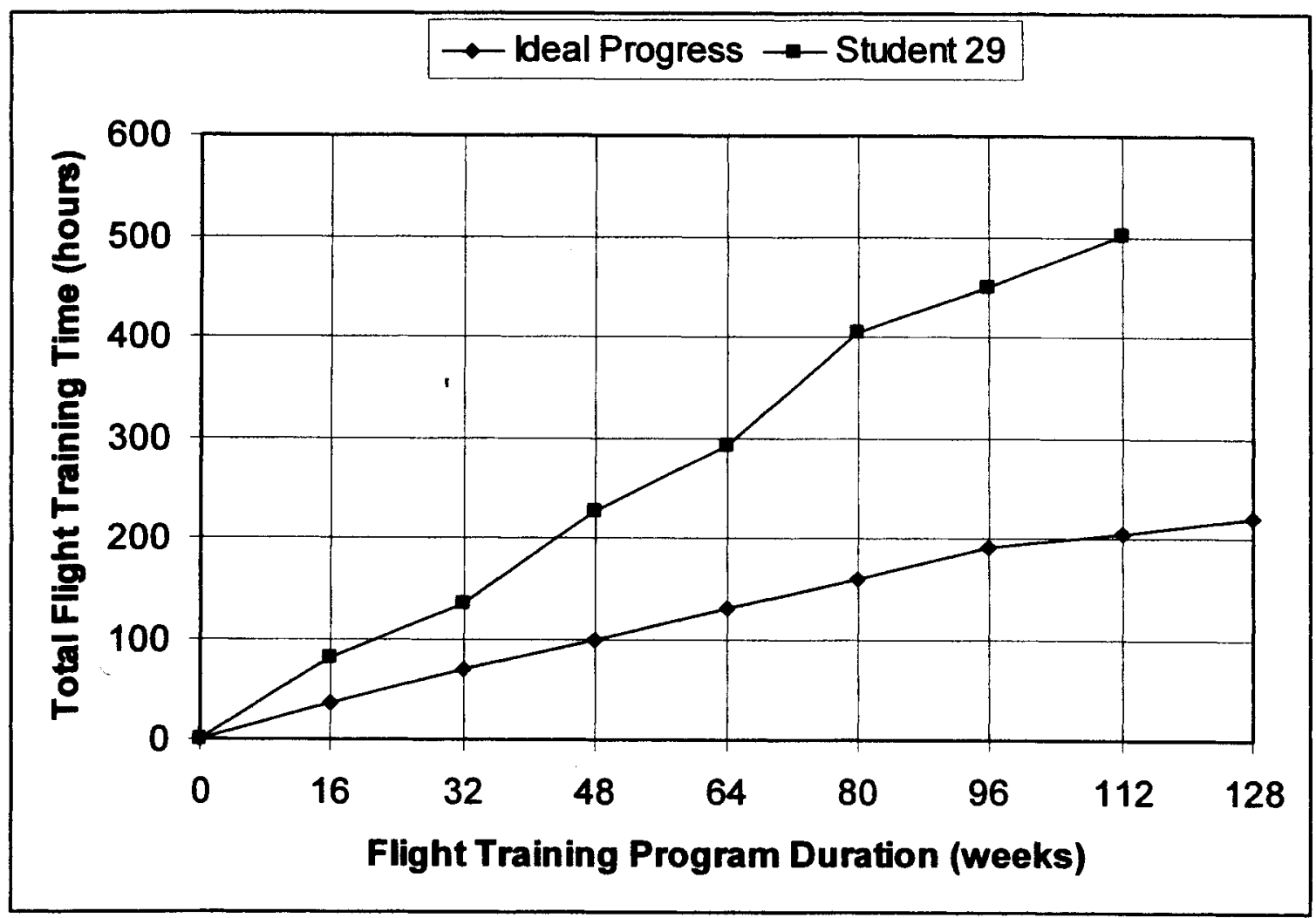

Figure 5: Flight training progress chart for Student 29 showing realized capacity and no flight training progress plateaus. 


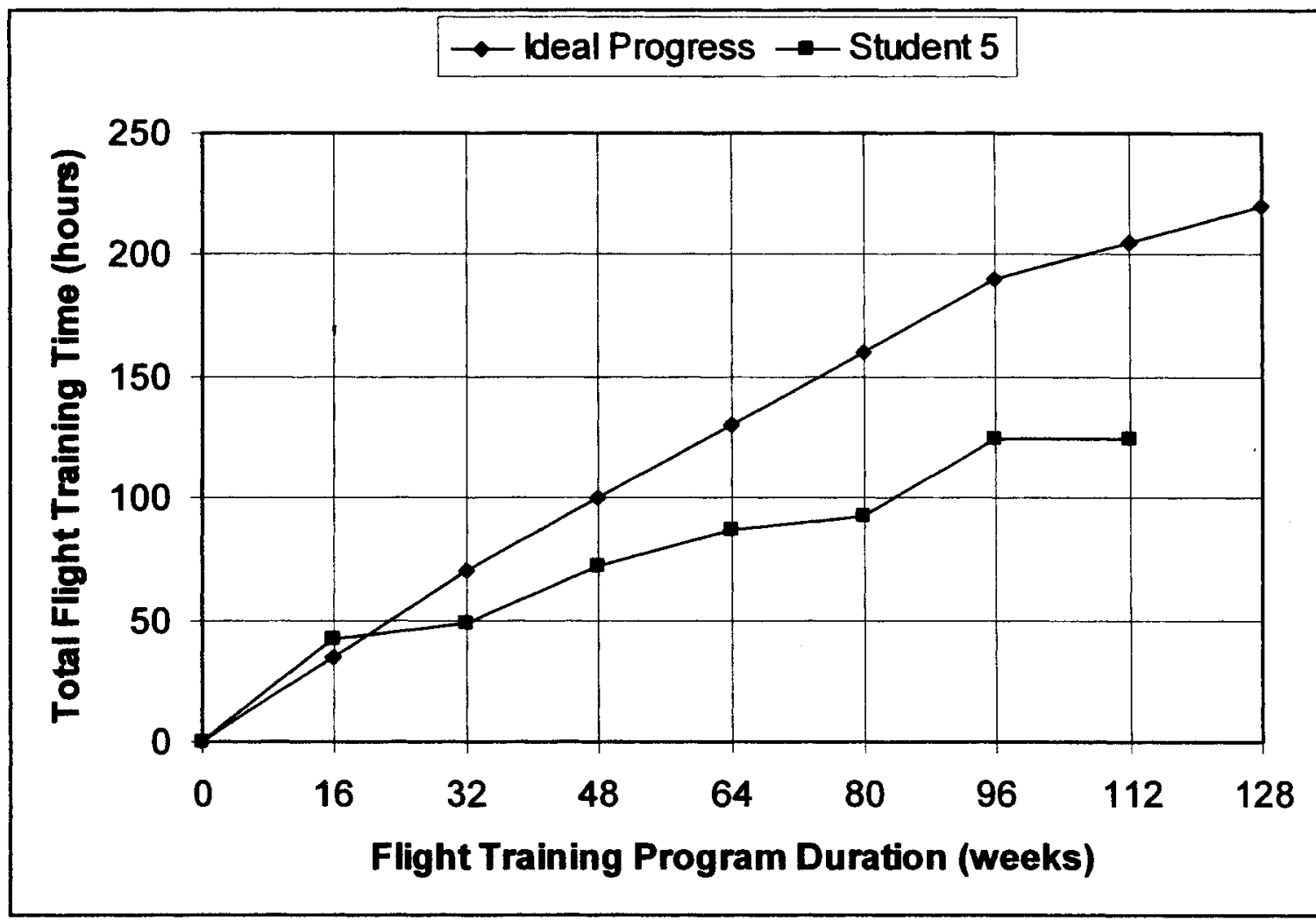

Figure 6: Flight training progress chart for Student 5 showing unrealized capacity and flight training progress plateaus. 


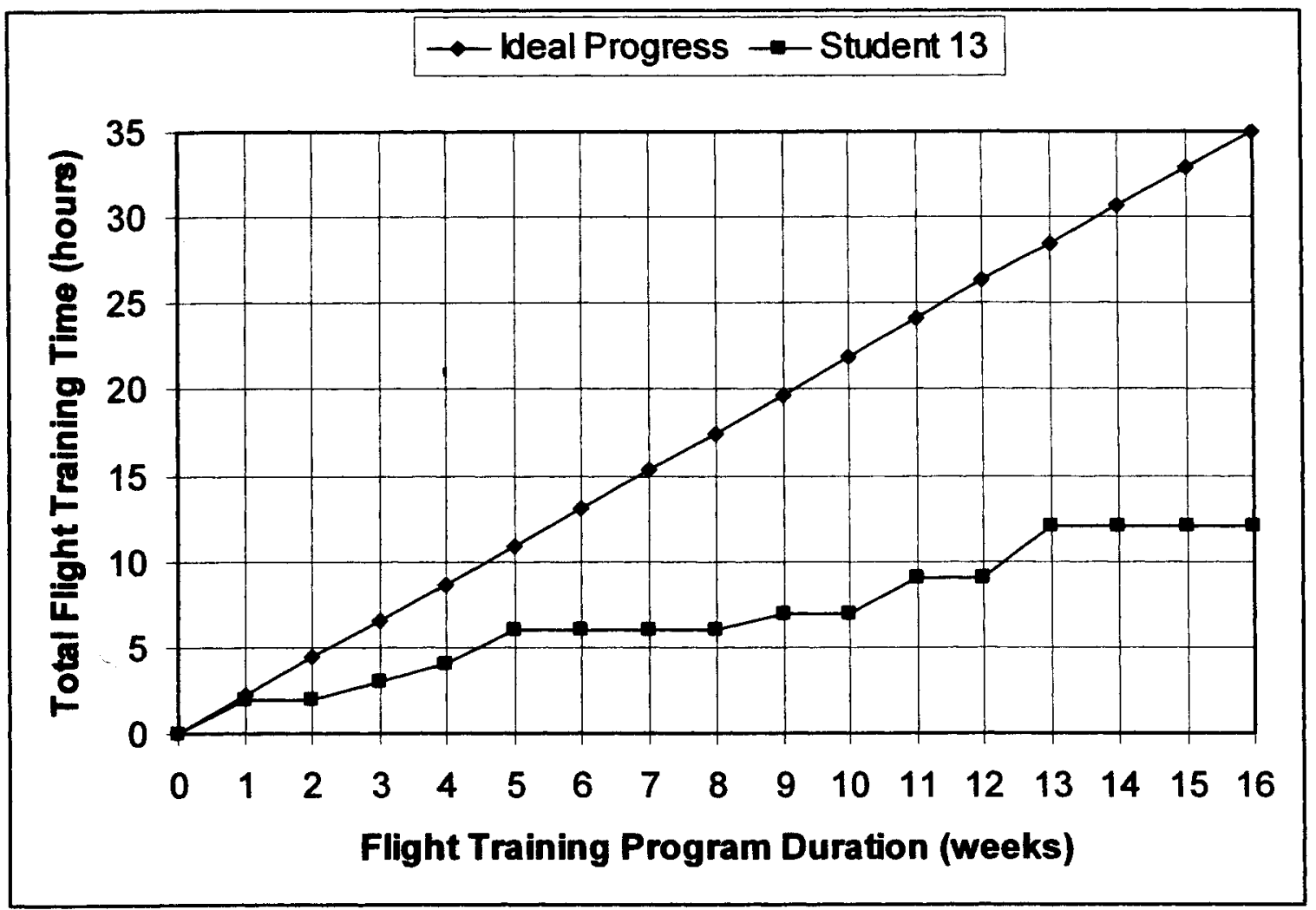

Figure 7: Flight Training Progress Chart illustrating progress plateaus in the first semester of a flight training program (Student 13). 


\section{Progress Plateaus}

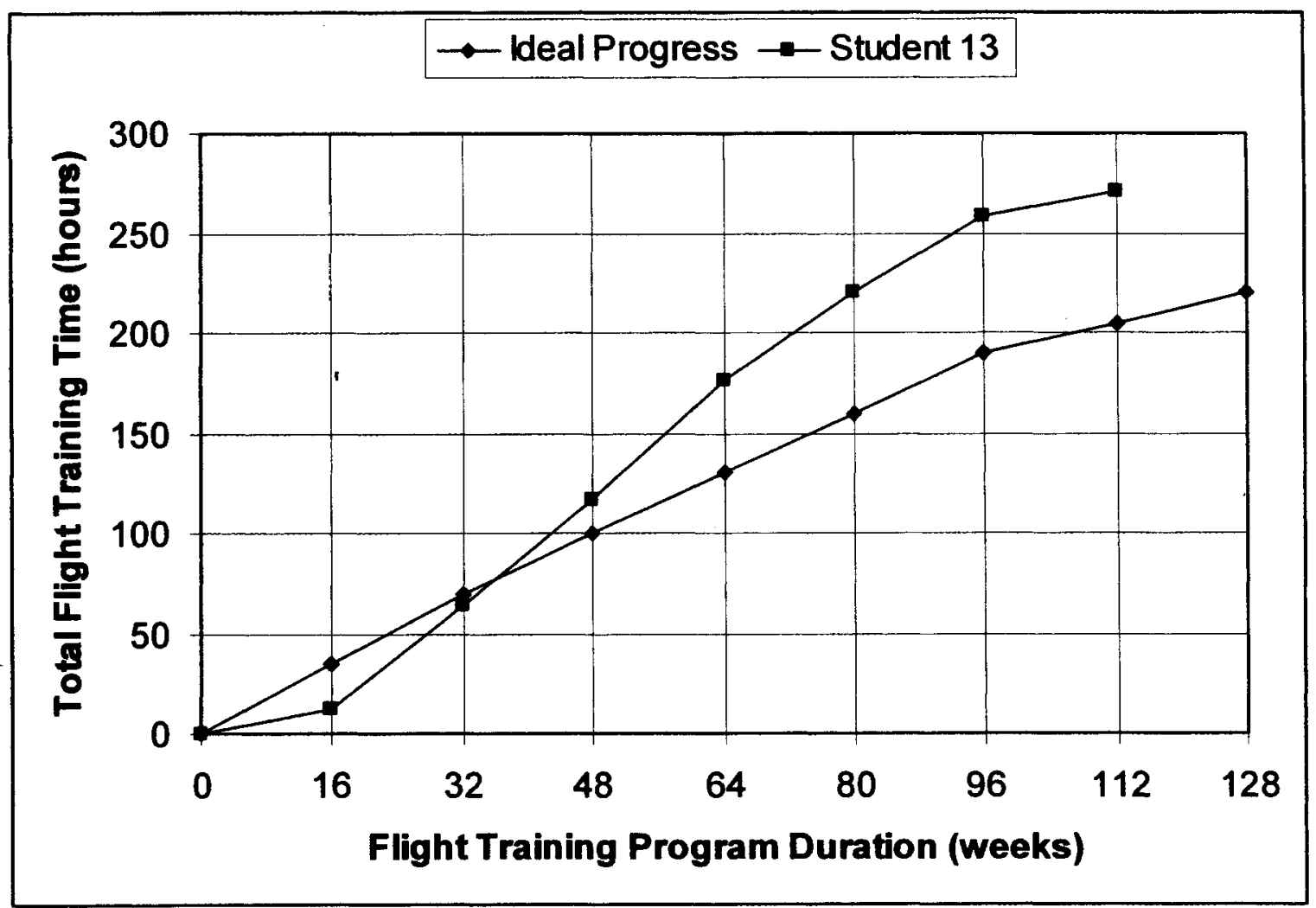

Figure 8: Flight Training Progress Chart for Student 13 illustrating how early flight training progress plateaus can be overcome. 